\title{
0 SINDICALISMO AINDA CONTA? PODERES SINDICAIS EM DEBATE NO CONTEXTO EUROPEU 1
}

Hermes Augusto Costa ${ }^{a}$

aé sociólogo, professor da Universidade de Coimbra e pesquisador do Centro de Estudos Sociais.

Coimbra, Portugal. E-mail: <hermes@fe.uc.pt>

Orcid: 0000-0001-7873-4440

http://dx.doi.org/10.1590/0102-259285/104

\section{Introdução}

Ao longo da última década, a Europa e, em especial, os países da periferia da zona euro, foram varridos por cenários de crise económica e social iniciados com a crise do subprime americano, em 2008. Numa Europa atravessada por assimetrias entre países centrais e periféricos, que secundariza a convergência económica e social que constara da lógica fundadora da ideia europeia (Reis, 2018, p. 180), as oportunidades para uma dignificação do trabalho são relegadas para segundo plano, como demonstraram as políticas de austeridade. Por sinal, políticas que, mais do que definidas por critérios económicos e financeiros, são algo de "iminentemente político" (Santos, 2012, p. 11) que produz impactos em diferentes planos: desigualdades, classe média,

\footnotetext{
${ }^{1}$ A reflexão empreendida neste texto insere-se no projeto de pesquisa "Rebuilding trade union power in the age of austerity: a review of three sectors" (PTDC/ IVC-SOC/3533/2014 - POCI-01-0145-FEDER-016808), a decorrer no Centro de Estudos Sociais da Universidade de Coimbra entre 2016 e 2018. O projeto tem o apoio financeiro da Fundação para a Ciência e Tecnologia (FCT/MEC) por meio de fundos nacionais e é cofinanciado pelo FEDER através do Programa Operacional Competitividade e Inovação COMPETE 2020.
} 
desemprego, endividamento das famílias ou sociedade-providência (Santos, 2012). Nesse sentido, a austeridade constitui-se como "forma de economia política de natureza regressiva" (Observatório Sobre Crises e Alternativas, 2014, p. 313), que modificou as relações sociais e redefiniu o lugar central do trabalho na economia. $\mathrm{E}$ as relações laborais $\mathrm{e}$ seus atores - em especial o sindicalismo - foram alguns dos alvos preferenciais dessa economia política regressiva.

Autoridades públicas e legisladores nacionais adotaram medidas de flexibilidade empresarial. Por um lado, medidas ditas temporárias, relacionadas com o tempo de trabalho (por exemplo, o aumento do tempo de trabalho ou as reduções nos pagamentos do trabalho suplementar) e com os contratos de trabalho atípicos (duração determinada, part-time, trabalho temporário etc.). Por outro lado, medidas de caráter permanente, relacionadas com a flexibilização das regras dos despedimentos ou com as alterações nos sistemas 260 de relações laborais e de negociação coletiva (Clauwaert e Schömman, 2012). Consequentemente, esse contexto adverso - marcado pelo reforço de assimetrias nas relações laborais e por um aumento da precariedade laboral - estimulou o crescimento de formas de protesto social, tanto no campo sindical como fora dele (Campos Lima e Artiles, 2014; Costa, Dias e Soeiro, 2014; Dias e Fernandes, 2016).

Basta olhar para o discurso da principal organização sindical europeia - a Confederação Europeia de Sindicatos (CES), fundada em 1973 - para constatar que, sendo produto do processo construção europeia e considerando a "Europa Social" como principal pilar política europeia (Degryse e Tilly, 2013), a CES se posiciona como forte adversária das políticas de austeridade. Aliás, algumas campanhas da CES - como "A pay rise for European workers is a matter of social justice. It's time for OUR recovery!" ou "Raise your voice for a Social Europe"2 -,

2 Disponível em: <https://bit.ly/2o42qhK>. Acesso em: 24 abr. 2018. 
testemunham bem o apelo transnacional no sentido de perseguir o crescimento económico e superar as desigualdades.

Perante um contexto generalizado de insatisfação e retrocesso civilizacional, importa recuperar (na primeira secção do texto) o legado histórico do sindicalismo na construção de direitos para o qual os sindicalistas europeus parecem, hoje, olhar de forma saudosista. Mas, não obstante o compreensível apelo da CES à "soma de esforços", esta organização - que em maio de 2018 tinha 45milhões de trabalhadores filiados, provenientes de 89 confederações sindicais nacionais de 39 países e de 10 federações sindicais europeias (Europe Trade Union Confederation, 2018) - continua a ter pela frente o grande desafio de ter de combinar um programa comum coerente com uma grande diversidade de experiências e tradições (Bernaciak, Gumbrell-McCormick e Hyman, 2014). Daí que seja inevitável, na secção seguinte deste texto, recordar distintas teorias e modelos sindicais, por sinal em reconhecimento de que existem não só "variedades de capitalismo" (Hall e Soskice, 2001), como, igualmente, "variedades de sindicalismo" (Frege e Kelly, 2004; Gumbrell-McCormick e Hyman, 2013, pp. 6-27).

$\mathrm{O}$ parágrafo anterior sugere, pois, que o sindicalismo está confrontado com influências externas (globalização económica, crise, austeridade, apropriação política das crises etc.) e com influências internas decorrentes das especificidades nacionais. Ora, sendo sabido que o sindicalismo não foi, designadamente no seu berço europeu, concebido como poder, mas, antes, como contrapoder, importa perceber em que medida, num cenário defensivo, podem ainda os atores sindicais fazer a diferença na sociedade. Nesse sentido, na terceira e na quarta seção do texto, faz-se, por um lado, um mapeamento analítico das principais formas de poder do sindicalismo e, por outro lado (de modo complementar), uma análise de quatro temas - representatividade sindical, independência, ação internacional e construção de alianças sociais - que são um corolário da discussão das formas de 
poder do sindicalismo e constituem um teste à perceção da sua importância social e política.

\section{A construção de direitos como legado histórico do sindicalismo}

O sindicalismo foi crucial na construção de direitos sociais e laborais. Desde logo, no contexto britânico, em que, entre 1780 e 1830, foi se fortalecendo uma classe operária dotada de consciência e identidade coletiva e com legitimidade para reivindicar melhores condições de vida e maior influência sobre o poder e a política. As primeiras associações de trabalhadores tinham um caráter secreto e seus membros faziam juramentos por meio dos quais se comprometiam com um conjunto de deveres, comportamentos e obrigações. As primeiras associações caracterizavam-se muito pela afirmação de identidade e por um caráter mutualista, o que significa que a componente reivindicativa

262 não ocupava aí um lugar central. A prioridade residia na tentativa de resolver carências absolutas dos trabalhadores e de procurar dotá-los de estruturas de proteção e solidariedade.

Foi com a Revolução Industrial que o "direito do trabalho" se construiu, em resultado da massificação da produção, da migração da população rural para os centros urbanos industrializados e, consequentemente, da busca de trabalho num contexto de ausência de poder de negociação/reivindicação mediante o patrão. Na verdade, um longo percurso até seu reconhecimento e afirmação. Nessa linha, as leis do trabalho foram, sem surpresas, direcionadas aos mais desprotegidos. Visaram, por exemplo, "regular o trabalho de crianças e mulheres, datando de 1819", na Inglaterra, “com leis progressivamente complementadas até 1878", e de "1891, em Portugal, seguindo-se um período de certa uniformização dos regimes laborais nos vários países europeus" (Dionísio, 2004, p. 1).

Dentre os progressos alcançados no domínio dos direitos laborais no plano internacional (sobretudo europeu), a 
conquista das oito horas de trabalho diárias/48 horas semanais, a criação da Organização Internacional do Trabalho (em 1919) e as convenções (tendo a primeira sido exatamente sobre o horário de trabalho) foram marcos essenciais de "uniformização e de regulação das relações sociolaborais à escala mundial" (Dionísio, 2004, p. 2).

Em especial depois da Segunda Guerra Mundial, consagrou-se a "idade de ouro" das conquistas laborais, assente na edificação de normas de cidadania laboral no local de trabalho e no desenvolvimento de políticas macroeconómicas favoráveis ao pleno emprego (Ross e Martin, 1999, p. 7). Num contexto no qual importa destacar marcos como a Declaração de Filadélfia (1944) e a Declaração Universal dos Direitos Humanos (1948), generalizaram-se, sobretudo no lado ocidental da Guerra Fria, um conjunto de leis e de direitos laborais, sindicais e sociais. O Estado-providência e o objetivo do pleno emprego configuraram-se, pois, como dois mecanismos redistributivos essenciais: o neocorporativismo consagrou-se como dispositivo institucional de fomento de consensos entre o governo e os interesses organizados (Regini, 1995, p. 8), e o fordismo como modelo de relação salarial dominante. Em todo esse trajeto de afirmação de direitos (tanto individuais quanto coletivos), o papel emancipatório do sindicalismo foi crucial (Costa, 2017b).

\section{As variedades do sindicalismo: revisitando teorias e modelos}

Falar das variedades do sindicalismo na Europa implicaria, por certo, uma incursão prévia por abordagens das relações laborais, pois estas funcionam como antecâmara das teorias e modelos do sindicalismo no contexto euro$\mathrm{peu}^{3}$. Reporto-me aqui apenas a algumas teorias e modelos, tomando como referência, entre outras, as propostas

\footnotetext{
3 Para uma análise de tais abordagens - sistémicas, marxistas, institucionalistas, da ação e de inspiração económica -, cf. Müller-Jentsch (1998).
} 
de Michael Poole (1981), Larson e Nissen (1987), Paquet, Tremblay e Gosselin (2004) e Hyman (2001). A meu ver, é possível distinguir dois conjuntos de teorias. O primeiro diz respeito às teorias morais e éticas e às teorias sobre as reações "psicológicas" ou defensivas mediante as primeiras condições de industrialização. Um segundo conjunto de teorias encontra-se situado no triângulo "mercado-classe-sociedade" (Hyman, 2001).

De acordo com as teorias e abordagens éticas e morais, os sindicatos são um produto de valores éticos, morais e religiosos que despontaram no século XIX. No final do século XIX, em A divisão do trabalho social, Émile Durkheim (1839) defenderia que a principal tarefa das sociedades industriais avançadas consistia num "trabalho de justiça”, que pressupunha tratar as relações sociais de acordo com critérios de crescente igualdade. Mais tarde, mas num sentido semelhante, John Rawls (1972) defenderia uma conceção geral de justiça 264 no movimento operário, capaz de garantir distribuição igualitária de liberdade, oportunidade, rendimento e riqueza. Em suma, o sindicalismo era visto como uma instituição moral baseada tanto em movimentos cristãos socialistas protestantes como na Igreja Católica Romana. No caso desta, as encíclicas papais - Rerum Novarum (1891), do Papa Leão XIII; Quadragesimo Anno (1931), do Papa Pio XI; ou Laborem Exercens (1981), do Papa João Paulo II - consideraram o sindicalismo como uma via de regeneração moral da sociedade (Larson e Nissen, 1987).

Por sua vez, os teóricos do sindicalismo enquanto reação psicológica ou defensiva em face das primeiras condições de industrialização (Poole, 1981, pp. 14-15) focaram-se nas respostas dos trabalhadores à perda de estatuto social e de identidade coletiva resultante da inovação tecnológica (Paquet, Tremblay e Gosselin, 2004). Mas, além disso, contestava-se também a influência potencialmente nociva dos intelectuais no movimento sindical, que fazia que o trabalho tivesse de 
lutar não apenas contra o capital, mas também contra os membros da intelligentsia que procuravam desviar o sindicalismo dos seus objetivos básicos, ainda que fosse suposto o intelectual enquadrar os programas dos sindicatos e moldar suas políticas (Perlman, 1987 [1928], p. 162).

O segundo conjunto de teorias remete para o triângulo "mercado, classe e sociedade". As teorias sindicais do "mercado" centram-se nas "condições económicas" do sindicalismo (Poole, 1981, pp. 15-16), isto é, no papel dos sindicatos enquanto instituições económicas e não morais, psicológicas ou revolucionárias. $\mathrm{O}$ business unionism americano, associado a categorias de trabalhadores relativamente qualificadas, exemplificou bem a conceção dos sindicatos enquanto atores económicos (Hyman, 2001, pp. 8-9) dotados de objetivos essenciais: satisfazer interesses concretos dos trabalhadores no emprego, no contexto da produção industrial; negociação coletiva como via para obter melhores condições de trabalho; mais "consciência do emprego" em vez de "consciência de classe" (Larson e Nissen, 1987, p. 131; Paquet, Tremblay e Gosselin, 2004, p. 302).

Em segundo lugar, as teorias da "classe" inspiraram-se na escola marxista e no reconhecimento de que "a moderna sociedade burguesa, saída do declínio da sociedade feudal, não aboliu os antagonismos de classe” (Marx e Engels, 1982 [1848], p. 107). Em todo o caso, a centralidade do conflito não foi exclusiva do pensamento marxista, destacando-se igualmente as teorias pluralistas que viram nos sindicatos uma forma institucionalizada de regulação social, sendo a negociação coletiva o meio pelo qual o conflito entre empregador e empregado seria regulado. Note-se, todavia, sobretudo ao longo da última década na periferia da zona Euro, que a questão da "classe" não desapareceu das relações laborais. Ora, o contexto laboral português, marcado pela destituição de direitos, precariedade, insegurança e exploração resultantes das políticas de austeridade, foi um exemplo disso (Costa, 
2012; Lehndorff, Dribbush e Schulten, 2017; Leite et al., 2014). Por sinal, um contexto adverso que parece replicar-se no Brasil, sobretudo desde que o governo Temer fez cair o governo Dilma e abriu clivagens na sociedade brasileira, de que a reforma trabalhista será apenas um exemplo. Assim, a "luta de classes" não poderá ser totalmente descartada, mesmo sabendo que é atravessada por várias tensões: entre intervenção política e pragmatismo economicista; entre militância (confronto) e acomodação (compromisso); entre uma solidariedade de classe ampla e comportamentos sectaristas (Hyman, 2001, pp. 28-30).

Por fim, as teorias da "sociedade" valorizam o papel democrático e integrador do sindicalismo, bem como o diálogo social. Na linha de Zoll (1998) e de Hyman (2001), é necessário um esforço suplementar para que o sindicalismo se consolide como ator da sociedade civil, tanto mais que o sindicalismo social-democrata, assente numa negociação ou 266 parceria institucionalizada com governos e empregadores, há muito terá perdido sua aura. Daí a necessidade de recuperar o papel de movimento social do sindicalismo e construir, tanto à escala nacional como supranacional, alianças com outras organizações da sociedade (Costa, 2008; 2015; Bieler, 2014; Hyman, 2002).

Essa exposição de teorias sindicais europeias se repercute na existência de modelos. A síntese dos "modelos do sindicalismo", proposta por Gumbrell-McCormick e Hyman (2013) e por Bernaciak, Gumbrell-McCormick e Hyman (2014), é um bom testemunho das "variedades do sindicalismo". Aqueles autores se baseiam em países da Europa Ocidental e elegem vários critérios de análise: filiação/densidade sindical; peso da ideologia; fronteiras entre setores, entre público e privado; estatuto ocupacional; democracia sindical; efeitos concretos da ação sindical etc. O resultado é uma distinção por quatro grupos de países: nórdicos, centrais, do sul e os de língua inglesa. 
Os países nórdicos (sobretudo a Suécia, Dinamarca, Noruega e Finlândia) são caracterizados por: sistemas de relações laborais baseados na institucionalização de compromissos de classe entre capital e trabalho; elevados níveis de sindicalização; ausência de divisões ideológicas; separação de organizações por empregados segundo trabalho manual, white collar e profissional ou graduado etc.

Por sua vez, os países centrais (Alemanha, Áustria, Suíça, Holanda e Bélgica) são caracterizados por: tradições consolidadas de parceria social; densidade sindical relativamente baixa - exceto na Bélgica; negociação coletiva combinada com disposições no sentido de estender acordos a empregadores não signatários; sistemas legais de conselhos de empresa normalmente dominados por representantes sindicais; Estados de bem-estar mais fracos do que nos países nórdicos, mas com espaço relevante para o envolvimento sindical na formulação de políticas públicas etc.

Em terceiro lugar, os países do sul (França, Itália, Espanha, Portugal e Grécia) são caracterizados por uma forte presença de partidos comunistas, bem como pela importância da ideologia no movimento sindical; apresentam relações laborais altamente politizadas; a regulamentação do emprego depende geralmente mais da legislação do que da negociação coletiva etc.

Por fim, os países de língua inglesa (Grã-Bretanha e Irlanda) estão mais próximos dos "mercados liberais"; aí os sindicatos são relativamente fragmentados ao longo das linhas ocupacionais e industriais; além disso, os sindicatos têm que granjear reconhecimento empresa a empresa (Bernaciak, Gumbrell-McCormick e Hyman, 2014, pp. 7-9).

\section{As fontes de poder sindical}

À luz da diversidade de teorias e modelos anteriormente expostos, cabe então perguntar: onde reside o poder sindical? Como se pode classificar? Poderá parecer 
estranho articular sindicalismo e poder, desde logo, se considerarmos que o poder está conotado com a política conduzida por governos, ao passo que o sindicalismo atua "à margem do poder". Além disso, na sua génese (no contexto da Revolução Industrial), as organizações sindicais - "espada da justiça" que defende os fracos e desfavorecidos (Gumbrell-McCormick e Hyman, 2013; Hyman, 2002) - foram concebidas como contrapoder ${ }^{4}$. Todavia, mesmo admitindo que a retórica da "crise do sindicalismo" se impôs em face dos discursos do poder sindical, não se podem deixar de mencionar alguns dos estudos que associam a atividade sindical a fontes de poder. Ao lançaram-se nesse desafio, tais estudos mais não fizeram do que identificar dimensões vulneráveis da ação sindical, mas, ao mesmo tempo, dimensões em que o sindicalismo poderia encetar renovadas estratégias de afirmação.

Jelle Visser (1995) apresentou, há mais de duas déca268 das, uma das análises mais consistentes sobre as fontes de poder sindical, distinguindo três tipos desse poder: organizacional, institucional e económico. O poder organizacional consiste na capacidade dos sindicatos de mobilizar e recrutar membros (reforçando a sindicalização); evitar fragmentações e divisões ideológicas; colaborar com estruturas partidárias, mas sem cair na dependência delas; ou ainda criar uma extensa organização externa com ramos concernentes à empresa e um controle centralizado dos processos de decisão. O poder institucional, por sua vez, está relacionado com os laços que os sindicatos estabelecem, por consulta, negociação e representação, com associações de empregadores e instituições públicas. Esse poder institucional tende a ser maior quando é concedido aos

\footnotetext{
${ }^{4} \mathrm{O}$ que, apesar de tudo, historicamente não invalidou a identificação do sindicalismo com orientações ideológicas distintas (revolucionárias, bolchevistas, reformistas, nacionalistas, corporativas, cristãs), por sinal, umas com maior distanciamento diante do poder do que outras.
} 
sindicatos um estatuto "semipúblico" e quando os governos apoiam explicitamente uma política de autoregulação entre empregadores e empregados. Por fim, o poder económico está associado ao padrão de qualificações dos membros de um sindicato (por exemplo, os sindicatos com trabalhadores qualificados possuem, segundo Visser, um amplo poder económico, em tudo semelhante ao dos controladores de tráfego aéreo ou aos pilotos de aviação). Esse poder económico - que normalmente é menor em períodos de recessão e desemprego - prende-se, pois, com a capacidade sindical para "influenciar" o mercado e será tanto maior quanto maior for a organização e a proteção institucional do sindicato, ou seja, num sinal de sinergia evidente com as duas fontes de poder anteriores.

Simultaneamente, Jensen, Madsen e Due (1995) identificaram duas fontes de poder complementares e, por sinal, em destaque no contexto de austeridade e retrocesso nos direitos sociais registado nos países da periferia da zona euro nos últimos anos: por um lado, um poder conflitual, associado a uma tendência dos sindicatos a contrariarem o poder do capital sempre que este põe em causa interesses sindicais; por outro lado, um poder político, pois os sindicatos estão investidos da capacidade para exercerem pressão sobre determinado sistema político sempre que ele for desestabilizador para as relações laborais (Jensen, Madsen e Due, 1995). Tais análises sobre as fontes de poder sindical foram, entretanto, retrabalhadas por Wright (2000), Silver (2003), Schmalz e Dörre (2013), Gumbrell-McCormick e Hyman (2013), McGuire (2014), Crouch (2017), entre outros. Recuperando algumas dessas análises, Lehndorff, Dribbush e Schulten (2017, pp. 9-11) procedem a uma sistematização das fontes de poder distribuída do modo explanado a seguir.

Por um lado, a ideia de poder estrutural baseia-se no poder de negociação dos trabalhadores no mercado de trabalho (ditado pela escassez de trabalhadores) e no 
processo de trabalho (ditado pela localização de trabalhadores). Ou seja, o poder estrutural dos trabalhadores será tanto maior quanto mais difícil for substituir trabalhadores por suas qualificações ou sua posição na cadeia de valor. Só indiretamente o poder sindical pode ser influenciado pelos sindicatos, sendo diretamente moldado pelo modelo particular de desenvolvimento socioeconómico nacional, bem como pela política social e económica e estratégias dos empregadores na restruturação das cadeias de valor e processos de trabalho.

O poder organizacional baseia-se quer na expressão numérica dos sindicatos, quer na capacidade de mobilização da filiação. Essa forma de poder depende da influência ditada pelas atividades dos próprios sindicatos. Existe, assim, uma influência recíproca entre a dimensão da filiação sindical e a capacidade de financiamento dos sindicatos. Se em alguns países o poder organizacional depende 270 das contribuições financeiras resultantes da filiação, em outros países os contributos (diretos ou indiretos) podem resultar de acordos coletivos ou da legislação.

O poder institucional é o resultado da presença de instituições de governação económica que moldam não apenas a capacidade dos sindicatos organizarem e representarem trabalhadores, mas também da sua posição na negociação coletiva. $\mathrm{O}$ poder institucional pode ser suportado indiretamente por regulações do mercado de trabalho (como salário mínimo ou subsídio de desemprego). Trata-se de uma forma de poder muito sensível à intervenção legislativa.

Por fim, o poder societal apresenta duas componentes: por um lado, a componente do poder colaborativo, traduzida na capacidade dos sindicatos construírem coligações no âmbito de redes na sociedade civil, inclusive com partidos políticos; por outro, a componente discursiva e comunicativa, traduzida na capacidade de os sindicatos influenciarem o discurso público e fixarem uma agenda. 


\section{Converter fraquezas em mecanismos de capacitação: quatro temas incontornáveis}

Após a sistematização das variedades de sindicalismo e das fontes de poder sindical, quais temas urgem ser discutidos como forma de perceber se os sindicatos ainda contam? A resposta a essa interrogação passa, na linha de Estanque, Costa e Silva (2015), por uma reflexão em torno de quatro temas: representatividade sindical, independência, ação internacional e construção de alianças sociais.

\section{A representatividade sindical}

Várias análises da evolução do sindicalismo contemporâneo na Europa veem na quebra da sindicalização um dos principais sinais reveladores da sua crise (Bernaciak, Gumbrell-McCormick e Hyman, 2014; Gumbrell-McCormick e Hyman; 2013; Waddington, 2014). E ainda que os níveis de sindicalização sejam variáveis - indo dos $70 \%$ nos países nórdicos, como Suécia $(68,8 \%)$ e Dinamarca $(67,6 \%)$, até valores bem mais baixos na Estónia $(7,6 \%)$ ou na França $(7,7 \%)$ (Sousa, 2011, p. 6) -, a tendência de retração tem se confirmado sobretudo no Sul e no Leste da Europa. No caso português, a tendência de perda de sindicalizados vem se acentuando nas três últimas décadas $-60,8 \%$ de sindicalizados em 1978, 35\% em 1988, 23,4\% em 2008, e estima-se que cerca de 19\% em 2015 (Stoleroff, 2013; Costa, Dias e Soeiro, 2014; Estanque, Costa e Silva, 2015).

Para Pedersini (2010), os indicadores de sindicalização atestam a influência dos sindicatos no domínio das relações coletivas de trabalho e da relação com outros atores sociais e políticos. Tais indicadores revelam o poder organizacional dos sindicatos (nos termos de uma das fontes de poder anteriormente mencionadas) e a capacidade de conquistarem o apoio dos trabalhadores em geral. Assim, as cotizações dos sócios constituem a principal fonte de receita sindical, algo 
crucial em países onde não existe qualquer tipo de subvenção estatal aos sindicatos, como sucede no caso português. $\mathrm{E}$ os meios materiais disponíveis condicionam muito a ação desenvolvida. Por sinal, a própria CES continua a depender dos recursos da Comissão Europeia como forma de compensar as cotizações provenientes dos associados.

A quebra de sindicalização explica-se, em parte, por fatores como: as transformações na legislação laboral, as quais geram transferências de rendimentos do trabalho para o capital (Leite et al., 2014); a variação dos contextos económicos, políticos, sociais e institucionais em que operam os sindicatos nos vários países (Crouch, 2017); o nível das desigualdades sociais e salariais; o grau de coordenação sectorial e nacional da negociação coletiva; a robustez das instituições de concertação e diálogo social e do Estado social; a participação dos sindicatos na gestão de sistemas de proteção social (Sousa, 2011, p. 7).

272 Mas é importante ter presente que não é apenas na evolução da sindicalização que reside a explicação para a aferição representatividade e influência dos sindicatos. Convirá, por isso, ter em conta outros fatores: o grau de cobertura da população ativa empregada pelas convenções coletivas de trabalho; a cobertura dos locais de trabalho pelos sindicatos ou outras formas de organização dos trabalhadores (comités de empresa, comissões de trabalhadores); os conflitos laborais; a potencial influência das organizações sindicais na formação das políticas públicas sociais e laborais; a efetiva capacidade de mobilização social (Sousa, 2011, p. 5).

\section{Independência sindical}

Já me referi à ausência de independência financeira da CES, uma vez que as receitas dos seus filiados são insuficientes. Ora, essa perda de independência financeira pode contribuir para pôr em causa a independência política. No caso português, por exemplo, o sistema de relações laborais foi sempre 
muito caracterizado por uma forte politização dos processos de negociação das condições de trabalho, por ligações das organizações sindicais e patronais ao sistema partidário, por uma centralidade do Estado na relação capital-trabalho, apesar do quadro jurídico e institucional assentar no princípio de autonomia das partes (Dornelas, 2009; Costa, 2012; Leite et al., 2014; Silva, 2007). Na verdade, poderá ser dito que, se existe uma autonomia sindical no plano das conceções, dos estatutos, na prática essa autonomia surge muito limitada.

Aliás, como alertam Estanque, Costa e Silva (2015, p. 125), os princípios da independência sindical são questionados quando está em jogo a relação com os partidos políticos, a qual é apelidada por Ebbinghaus (1995) como relação de "gémeos siameses". Tais interligações apresentam várias formas: o "modelo Leninista", em que o partido procura controlar as políticas e ações do sindicato; o caso britânico, em que os sindicatos criaram o Partido Trabalhista; o padrão social-democrata, que envolve "interdependência e simbiose"; ou ainda a posição em que os sindicatos, mesmo que politicamente engajados, recusam quaisquer alianças com partidos políticos (Hayward, 1980 apud GumbrellMcCormick e Hyman, 2013, p. 136). A regulação do mercado de trabalho parece, pois, configurar-se como uma questão de poder - e recorde-se aqui a ideia de poder institucional sistematizada por Lehndorf, Dribbusch e Schulten (2017), mas igualmente a componente colaborativa do poder societal -, tanto mais que os sindicatos são protagonistas na cena política e, nesse sentido, influenciam a forma como o Estado molda as regras do jogo no mercado de trabalho, a negociação coletiva e os processos de mobilização da ação coletiva (Hyman e Grumbrell-McCormick, 2010). Foi, pois, com esse propósito que alianças históricas entre sindicatos e partidos de esquerda, bem como com partidos e forças democratas cristãs progressistas, foram promovidas em prol da dignificação e influência sociopolítica dos trabalhadores. 
O problema é que, segundo Ross e Martin (1999), na virada para este século a ligação orgânica entre sindicatos e partidos de esquerda abandonou a esperança de transformação do capitalismo. As mudanças políticas que ocorrem em cada país, associadas à globalização da economia, tornaram pouco fiáveis as alianças de outrora. Os partidos de esquerda, mesmo que possam ter sido reformistas quando foram governo, guiaram-se cada vez menos pelas orientações do mundo do trabalho, tornando-se "chapéus-de-chuva das novas elites tecnocráticas cujas ideias provêm mais da Escola Nacional de Administração, do Economist ou do Finantial Times do que do socialismo" (Ross e Martin, 1999, p. 15).

Conforme Estanque, Costa e Silva (2015, p. 129), uma vez que a relação dos sindicatos com os partidos é, hoje, mais perversa do que virtuosa, é indispensável distinguir entre conteúdos "modernos" e "conservadores" no mundo do trabalho de modo a perceber se o que emana das agendas polí274 ticas dominantes é a força do pragmatismo do poder económico-financeiro ou um sentido progressista e emancipatório.

Em última análise, como bem resumem Lehndorf, Dribbusch e Schulten (2017, p. 29), não se espera que os sindicatos abdiquem da sua autonomia e se substituam aos partidos políticos. No entanto, em resultado das várias crises vivenciadas ao longo da última década, em alguns países europeus onde os sindicatos tiveram aliados políticos existe um vazio político que abriu caminho à intromissão de partidos mais conservadores. Daí que, independentemente das especificidades de cada país, os sindicatos na Europa busquem recuperar o seu core business, isto é, a melhoria das condições de trabalho e os direitos sociais outrora conquistados. É no recuperar dessa força política que os sindicatos podem reavivar do seu poder institucional ${ }^{5}$.

\footnotetext{
${ }^{5}$ No contexto português, desde novembro de 2015, um governo socialista propôs-se a "virar a página da austeridade", no que contou com a aliança com outras forças políticas (Bloco de Esquerda e Partido Comunista, partidos tradicionalmente
} 


\section{A ação internacional}

A ação internacional é uma ambição antiga do sindicalismo, celebrizada no apelo "Proletários de todos os países, uni-vos!" feito por Marx e Engels no Manifesto do Partido Comunista (1848). Em meu entender, esse tema passou despercebido (ou pelo menos foi subvalorizado) na análise das fontes de poder anteriormente sistematizada. Em boa medida porque a construção de um corpo de teorias do sindicalismo internacional (Ramsay, 1999) ficou refém das produções realizadas ao abrigo dos sistemas nacionais de relações laborais, o que, por consequência, fragilizou uma desnacionalização do próprio sindicalismo (Streeck, 1998; Traxler e Schmitter, 1995). Ainda assim, as questões da militância sindical transnacional continuam na ordem do dia $^{6}$.O facto de nem sempre existir (como assinalei anteriormente) uma verdadeira independência financeira e, sobretudo, política do sindicalismo foi também um condicionador das estratégias de integração sindical internacional, como sucedeu no caso português com a conturbada filiação da Confederação Geral dos Trabalhadores Portugueses (CGTP) na CES (Costa, 1998). De igual modo, a CGTP nunca chegou a filiar-se na Confederação Sindical Internacional (CSI), criada em 2006. Essa atitude revelou "constrangimentos de ordem política e ideológica" e terá significado "empurrar para debaixo do tapete um problema importante, ou ignorar, menosprezar ou, pura e simplesmente, esmagar uma parte significativa das suas organizações e dos seus membros" (Lança, 2010, pp. 19-20). Esse exemplo ocorrido na CGTP é apenas um dos vários fatores

mais próximos das causas do movimento sindical, em especial o segundo), conferindo sinais de esperança ao sindicalismo. Simultaneamente, um clima genérico de recuperação económica deu legitimidade aos sindicatos para reclamarem maior atenção ao conteúdo das suas agendas.

${ }^{6}$ A esse propósito, cf. o dossiê temático "Trabalhadores, Sindicatos e a Transnacionalização da Militância" (Rombaldi e Tomizaki, 2017). 
inibidores da cooperação sindical transnacional, tais como: a prioridade concedida à regulação laboral nacional (regimes jurídicos, salários e condições de trabalho); uma força de trabalho mundial sindicalizada de apenas $7 \%$ da população mundial (International Trade Union Confederation, 2014); uma escassez de recursos financeiros (sobretudo em contexto de crise) para potenciar deslocações em massa de trabalhadores em protesto de um país para outro, não obstante os dispositivos eletrónicos que hoje permitem encurtar distâncias; uma incorporação de estratégias de competição e conflitualidade nos discursos e práticas sindicais transnacionais; a subversão de direitos laborais nas empresas multinacionais; a fraqueza (com exceção da Organização Internacional do Trabalho) dos canais de representação dos interesses laborais no plano transnacional etc. (Costa, 2008; 2017a).Perante a exposição desses obstáculos, torna-se urgente que as organizações sindicais nacionais concedam 276 maior espaço a uma "política de relações internacionais". De tal política decorre um leque de potencialidades: campanhas de solidariedade entre organizações sindicais de diferentes países; partilha de experiências de resistência laboral; celebração de acordos-quadro globais entre multinacionais e federações sindicais globais; globalização de valores essenciais do sindicalismo - defesa da paz, luta contra a pobreza, exclusão social, racismo e xenofobia; organização de redes internacionais e múltiplas formas de protesto público; fusão de sindicatos como estratégia de reforço da capacidade de organização laboral transnacional; reforço da agenda do trabalho digno da OIT e dos diálogos do centenário sobre o futuro do trabalho (Ryder, 2015) etc.

\section{A construção de alianças sociais}

A construção de alianças entre o sindicalismo e organizações não sindicais há muito vem prendendo a atenção de estudiosos internacionais do sindicalismo e dos movimentos 
de precários. Trata-se de uma discussão em redor da ideia do "sindicalismo de movimento social" (Köhler e Jiménez, 2015; Lambert e Webster, 1988; Moody, 1997; Munck, 1988; Scipes, 1992; Seidman, 1994; Tapia e Alberti, 2018 [no prelo]) ou de um "novo sindicalismo social" (Waterman, 2004, 2012). Como refere Kim Moody (1997, pp. 289-290), trata-se de incluir "pessoas de uma variedade de tendências e [...] organizações tão diferentes como sindicatos e redes oposicionistas". Entendem-se, assim, as lutas dos trabalhadores "meramente como um entre muitos esforços de mudar qualitativamente a sociedade, e não como o único local de luta política e mudança social ou mesmo o local principal" (Scipes, 2000, p. 6). Isto posto, ao defender-se uma "cidadania fora do espaço da produção", convoca-se o sindicalismo "a articular-se com outros movimentos sociais progressistas, movimentos de consumidores, ecológicos, antiracistas, feministas etc." (Santos, 1995, p. 135), fazendo apelo a uma "cultura democrática de cidadania ativa para além da fábrica" (Santos, 1995, p 139).

Um dos mais empenhados ativistas dessa perspetiva foi Peter Waterman (2004, 2012). Para o autor, mais do que falar em sindicalismo de movimento social (conceito identificado com organizações nacionais específicas, com certas tendências de cariz militante e com o Sul), deveria falar-se de "novo sindicalismo social", cujos traços principais são: a defesa do trabalho assalariado (não apenas como modo de reclamar melhores salários, mas de garantir maior controle do processo produtivo, dos investimentos, das novas tecnologias, das relocalizações da produção, da subcontratação e das políticas de educação e formação); as ações de luta contra relações e métodos de trabalho hierárquicos, autoritários e tecnocráticos e em favor de práticas sociais e ambientalmente úteis, da redução do horário de trabalho ou da partilha do trabalho doméstico; a promoção de articulações e formas de diálogo com outros movimentos e comunidades 
não sindicalizados; o incentivo da democracia de base e o encorajamento de relações horizontais diretas tanto entre trabalhadores como entre estes e outras forças sociais democráticas/populares; etc.

Se é certo que todas essas possibilidades de abertura do sindicalismo a outros temas - multiculturalismo, cidadania, ambiente, diferença sexual etc. - pairam no ar, a cooperação sindical com movimentos sociais específicos ou associações de trabalhadores precários deixa muito a desejar (Braga e Marques, 2017; Costa, 2015; Gumbrell-McCormick, 2011; Lucio, Marino e Connolly, 2017). O que significa que o sindicalismo de movimento social está preso a preocupações táticas em vez de constituir uma aposta estratégica (Tapia e Alberti, 2018 [no prelo]).

Portanto, é crucial que o sindicalismo seja capaz de replicar exemplos não só à escala nacional como à escala europeia. Como sucedeu com a "Iniciativa europeia de 278 cidadãos sobre a água como direito humano", uma ampla aliança de grupos de cidadãos e representantes sindicais dos serviços públicos (com destaque para a Federação Europeia de Sindicatos dos Serviços Públicos), que mobilizou quase dois milhões de assinaturas. A iniciativa baseou-se em três demandas principais: a) reconhecimento pela União Europeia do direito humano à água e ao saneamento e sua inscrição na legislação comunitária; b) não liberalização dos serviços de água na União Europeia; c) acesso à água e ao saneamento para todos em todo o mundo. Dessa forma, juntaram-se preocupações sindicais (buscando manter o fornecimento de água em mãos públicas) e de grupos de cidadãos (clamando por acesso universal a água potável a preços acessíveis). Como bem assinalou Bieler (2014, p. 126), ao transcender o foco no local de trabalho, o direito de acesso à água potável permitiu aos sindicatos aliarem-se com outros movimentos sociais, ampliando solidariedades e resistências. 


\section{Conclusão: sim, o sindicalismo ainda conta!}

Ainda que os temas aqui analisados (representatividade, independência, ação internacional e construção de alianças) anunciem fraturas no sindicalismo, eles não deixam de constituir um teste ao poder do sindicalismo e à sua reinvenção. Mesmo não se tratando de um desafio novo, a renovação sindical é, hoje, na Europa e no mundo uma questão-chave para que o sindicalismo seja merecedor de maior confiança e influência na sociedade. Em estudos anteriores (Costa e Estanque, 2011; Leite et al., 2014; Silva, 2007; Estanque, Silva e Costa, 2015; Costa, 2017b) foram elencados vários caminhos para o sindicalismo que considero indispensáveis em qualquer parte do mundo. Além de colocarem ao rubro, se não todas, pelo menos algumas da fontes de poder em debate neste texto, tais caminhos enunciam vários compromissos fundamentais:

- reforço da vigilância sobre as formas e condições de trabalho;

- incremento da representatividade em sectores mais precários;

- organização de camadas subalternas das estruturas sindicais (jovens, mulheres, desempregados, subcontratados, imigrantes, minorias étnicas...);

- fomento de modus operandi baseados no ciberativismo das redes sociais e no sindicalismo eletrónico;

- qualificação de quadros e dirigentes sindicais, quer por meio de iniciativas próprias, quer de convénios com universidades e centros de pesquisa para que seja tão lícito elogiar o sindicalismo quanto submetê-lo a um exercício de análise crítica;

- valorização tanto do papel do conflito, quando os direitos sociolaborais são postos em causa, quanto do papel 
da negociação entre sindicatos e entre estes e empregadores e governos, sempre que dela decorrer um upgrade de mecanismos de regulação laboral que sejam portadores de maior dignidade para quem trabalha.

Muitos desses compromissos estão há muito identificados. Mantê-los em agenda servirá para mostrar que o sindicalismo, mesmo contra todas as adversidades, ainda conta. Na Europa e em qualquer lugar!

\section{Hermes Augusto Costa}

é Sociólogo, professor da Universidade de Coimbra e pesquisador do Centro de Estudos Sociais.

\section{Bibliografia}

BERNACIAK, Magdalena; GUMBRELL-MCCORMICK, Rebecca; HYMAN, Richard. 2014. European trade unionism: from crisis to renewal? Brussels: European Trade Union Institute, report n. 133.

280 BIELER, Andreas. 2014. Transnational labour solidarity in (the) crisis. Global Labour Journal, v. 5, n. 2, pp. 114-133. Disponível em: <https:// bit.ly/2LIP3JR $>$. Acesso em: 15 jan. 2018.

BRAGA, Ruy; MARQUES, Joana. 2017. Trabalho, globalização e contramovimentos: dinâmicas da ação coletiva do precariado artístico no Brasil e em Portugal. Sociologias, v. 19, n. 45, pp. 52-81.

CAMPOS LIMA, Maria da Paz; ARTILES, Antonio Martin. 2014.

Descontentamento na Europa em tempos de austeridade: da ação coletiva à participação individual no protesto social. Revista Crítica de Ciências Sociais, n. 103, pp. 137-172.

CLAUWAERT, Stefan; SCHÖMANN, Isabelle. 2012. The crisis and national labour law reforms: a mapping exercise. Brussels: European Trade Union Institute. pp. 1-19.

COSTA, Hermes Augusto. 1998. A globalização do sindicalismo como desafio: a adesão da CGTP à CES. Revista Crítica de Ciências Sociais, n. 51, pp. 185-188.

. 2008. Sindicalismo global ou metáfora adiada? discursos e práticas transnacionais da CGTP e da CUT. Porto: Afrontamento.

2012. From Europe as a model to Europe as austerity: the impact of the crisis on Portuguese trade unions. Transfer: European Review of Labour and Research, v. 18, n. 4, pp. 397-410. 
2015. Le syndicalisme portugais et l'austerité : entre la force des protestations et la fragilité des alliances. Relations Industrielles/Industrial Relations, v. 70, n. 2, pp. 262-284.

2017a. Conselhos de empresa europeus militantes? obstáculos, acordos e boas práticas à luz da experiência portuguesa na VW.

Sociologias, v. 19, n. 45, pp. 82-114.

2017b. Defender o trabalho para proteger as pessoas: os desafios da intervenção sindical. In: ROXO, Manuel (org.). Trabalho sem fronteiras? o papel da regulação. Coimbra: Almedina, pp. 241-254.

COSTA, Hermes Augusto; DIAS, Hugo; SOEIRO, José. 2014. As greves e a austeridade em Portugal: olhares, expressões e recomposições. Revista Crítica de Ciências Sociais, n. 103, pp. 173-202.

COSTA, Hermes Augusto; ESTANQUE, Elísio. 2011. Conclusão: condições para um sindicalismo com futuro. In: ESTANQUE, Elísio; COSTA, Hermes Augusto (orgs.). O sindicalismo português e a nova questão social: crise ou renovação? Coimbra: Almedina, pp. 171-174.

CROUCH, Colin. 2017. Membership density and trade union power. Transfer: European Review of Labour and Research, v. 23, n. 1, pp. 47-61.

DEGRYSE, Christophe; TILLY, Pierre. 2013. 1973-2013 : 40 ans d'histoire de la Confédération européenne des syndicats. Brussels: European Trade Union Institute.

DIAS, Hugo; FERNANDES, Lídia. 2016. The November 2012 general strike and anti-austerity protests: analysis from the Portuguese case. Workers of the World: International Journal on Strikes and Social Conflicts, v. 1 , n. 8 , pp. 16-38.

DIONÍSIO, Joaquim. 2004. O direito do trabalho e o modelo social europeu. Janus: Anuário de Relações Exteriores, n. 8, não paginado. Disponível em: <https://bit.ly/2LNpQny>. Acesso em: 31 maio 2018. DORNELAS, António. 2009. Perante a crise: problemas e perspectivas do emprego, do trabalho e da equidade social em Portugal. Finisterra, n. 65-66, pp. 101-133.

EBBINGHAUS, Bernhard. 1995. The siamese twins: citizenship rights, cleavage formation, and Party-Union Relations in Western Europe. International Review of Social History, v. 40, pp. 51-89. Suplemento 3.

ESTANQUE, Elísio; COSTA, Hermes Augusto. 2014. Trabalho, precariedade e rebeliões sociais. Revista Crítica de Ciências Sociais, n. 103, pp. 3-8.

ESTANQUE, Elísio; COSTA, Hermes Augusto; SILVA, Manuel Carvalho. 2015. O futuro do sindicalismo na representação sociopolítica. In: FREIRE, André (org.). O futuro da representação política democrática. Lisboa: Nova Vega, pp. 119-142. 
EUROPE TRADE UNION CONFEDERATION. 2018. Organisation and people. Disponível em: <https://bit.ly/2v6oluP > Acesso em: 31 maio 2018. FREGE, Carola; KELLY, John (eds.). 2004. Varieties of unionism: strategies for union revitalization in a globalizing economy. Oxford. Oxford University Press.

GUMBRELL-MCCORMICK, Rebecca; HYMAN, Richard. 2013. Trade Unions in Western Europe: hard times, hard choices. Oxford: Oxford University Press.

HALL, Peter; SOSKICE, David (eds.). 2001. Varieties of capitalism: the institutional foundations of comparative advantage. Oxford: Oxford University Press.

HYMAN, Richard. 2001. Understanding European trade unionism: between market, class and society. London: Sage. 2002. Europeização ou erosão das relações laborais? Revista Crítica de Ciências Sociais, n. 62, pp. 7-32.

HYMAN, Richard; GUMBRELL-MCCORMICK, Rebecca. 2010. Trade unions politics and parties: is a new configuration, possible? European Review of Labour and Research, v. 16, n. 3, pp. 315-331.

INTERNATIONAL TRADE UNION CONFEDERATION. 2014. Building workers' power: Congress record. Brussels: International Trade Union Confederation.

JENSEN, Carsten Strøby; MADSEN, Jørgen Steen; DUE, Jesper. 1995. A role for pan-European trade union movement? possibilities in European IR-regulations. Industrial Relations Journal, v. 26, n. 1, pp. 4-18. KÖHLER, Holm-Detlev; JIMÉNEZ, José Pablo Calleja. 2015. “They don't represent us!” opportunities for a social movement unionism strategy in Spain. Relations Industrielles/Industrial Relations, v. 70, n. 2, pp. 240-261.

LAMBERT, Rob; WEBSTER, Eddie. 1988. The re-emergence of political unionism in contemporary South Africa? In: COBBETT, William; COHEN, Robin (eds.). Popular struggles in South Africa. London: James Currey. pp. 20-41.

LANÇA, Florival. 2010. Inter Nacional. Porto: Profedições.

LARSON, Simeon; NISSEN, Bruce (eds.). 1987. Theories of the labor movement. Detroit: Wayne State University Press.

LEHNDORFF, Steffen; DRIBBUSH, Heiner; SCHULTEN, Thorsten. 2017. European trade unions in a time of crises: an overview. In: LEHNDORFF, Steffen; DRIBBUSH, Heiner; SCHULTEN, Thorsten (eds.). Rough waters: European trade unions in a time of crisis. Brussels: European Trade Union Institute. pp. 7-34. 
LEITE, Jorge et al. 2014. Austeridade, reformas laborais e desvalorização do trabalho. In: OBSERVATÓRIO SOBRE CRISES E ALTERNATIVAS (org.). A economia política do retrocesso: crise, causas e objetivos. Coimbra: Almedina; CES, pp. 127-188.

LUCIO, Miguel Martínez; MARINO, Stefania; CONNOLLY, Heather. 2017. Organising as a strategy to reach precarious and marginalized workers: a review of debates on the role of the political dimension and the dilemmas of representation and solidarity. Transfer: European Review of Labour and Research, v. 23, n. 1, pp. 31-46.

MARX, Karl; ENGELS, Frederich. 1982. Manifesto do Partido Comunista. In: BARATA-MOURA, José et al. (orgs.). Marx e Engels: obras escolhidas em três tomos. Lisboa: Avante, v. 1, pp. 106-136.

MCGUIRE, Donna. 2014. Analysing union power, opportunity and strategic capability: global and local union struggles against the General Agreement on Trade in Services (GATS). Global Labour Journal, v. 5, n. 1, pp. 45-67.

MOODY, Kim. 1997. Workers in a lean world: unions in the international economy. London: Verso.

MÜLLER-JENTSCH, Walther. 1998. Les théories des relations industrielles : une mise en perspective. Sociologie du Travail, v. 40, n. 2, pp. 233-262.

MUNCK, Ronaldo. 1988. The new international labour studies: an introduction. London: Zed Books.

OBSERVATÓRIO SOBRE CRISES E ALTERNATIVAS. 2014. Sete propostas alternativas para reconstituir a economia, a sociedade e a política. In: REIS, José (org.). A economia política do retrocesso: crise, causas e objetivos. Coimbra: Almedina, pp. 309-323.

PAQUET, Renaud; TREMBLAY, Jean-François; GOSSELIN, Eric. 2004. Des théories du syndicalisme: synthèse analytique et considérations contemporaines. Relations Industrielles/Industrial Relations, v. 59, n. 2, pp. 295-320.

PEDERSINI, Roberto. 2010. Trade union strategies to recruit new groups of workers. Dublin: Eurofound. Disponível em: <https://bit.ly/2LB4RYk>. Acesso em: 31 maio 2018.

PERLMAN, Selig. 1987. A theory of the labor movement. In: LARSON, Simeon; NISSEN, Bruce (eds.). Theories of the labor movement. Detroit: Wayne State University Press, pp. 161-173.

POOLE, Michael. 1981. Theories of trade unionism: a sociology of industrial relations. London: Routledge.

RAMSAY, Harvie. 1999. In search of international union theory. In: WADDINGTON, Jeremy (ed.). Globalization and patterns of labour resistance. London: Mansell, pp. 192-219. 
RAWLS, John. 1972. A theory of justice. Oxford: Oxford University Press. REGINI, Marino. 1995. Uncertain boundaries: the social and political construction of European economies. Cambridge: Cambridge University Press.

REIS, José. 2018. A economia portuguesa: formas de economia politica numa periferia persistente (1960-2017). Coimbra: Almedina.

ROMBALDI, Maurício; TOMIZAKI, Kimi. 2017. Trabalhadores, sindicatos e a transacionalização da militância. Sociologias, v. 19, n. 45, pp. 14-22.

ROSS, George; MARTIN, Andrew. 1999. European unions face the millennium. In: MARTIN, Andrew; ROSS, George (orgs.). The brave new world of European labor: European trade unions at the millennium. New York: Berghan, pp. 1-25.

RYDER, Guy. 2015. The future of work: centenary initiative. Geneva: International Labour Office.

SANTOS, Boaventura de Sousa. 1995. Teses para renovação do sindicalismo em Portugal, seguidas de um apelo. Vértice, n. 68, pp. 132-139.

2012. Portugal: ensaio contra a autoflagelação. Coimbra: Almedina.

SCHMALZ, Stefan; DÖRRE, Klaus. 2013. El planteamiento de los recursos del poder. Ciudad de México: Fundación Friedrich Ebert. Disponível em: <https:/ / bit.ly/2v3GMiE>. Acesso em: 25 maio 2018.

284 SCIPES, Kim. 1992. Understanding the new labor movements in the "Third World": the emergence of social movement unionism. Critical Sociology, v. 19, n. 2, pp. 81-101.

SEIDMAN, Gay. 1994. Manufacturing militance: workers' movements in Brazil and South Africa, 1970-1985. Berkeley: University of California Press.

SILVA, Manuel Carvalho. 2007. Trabalho e sindicalismo em tempo de globalização: reflexões e propostas. Lisboa: Círculo de Leitores.

SILVER, Beverly. 2003. Forces of labor: workers' movements and globalization since 1870. Cambridge: Cambridge University Press.

SOUSA, Henrique. 2011. Sindicalização: a vida por detrás das estatísticas (alguns problemas metodológicos). Lisboa: FCSH; Universidade Nova.

STOLEROFF, Allan. 2013. A crise e as crises do sindicalismo: há uma revitalização possível? In: VARELA, Raquel (org.). A segurança social é sustentável: trabalho, Estado e segurança social em Portugal. Lisboa: Bertrand, pp. 207-39.

STREECK, Wolfgang. 1998. The internationalization of industrial relations in Europe: prospects and problems. Politics $\mathcal{E}$ S Society, v. 26, n. 4, pp. 429-459.

TAPIA, Maite; ALBERTI, Gabriella. 2018 [no prelo]. Social movement unionism: a toolkit of tactics or a strategic orientation? a critical 
assessment in the field of migrant workers campaigns. In: JÜRGEN, Grote; WAGEMANN, Claudius (eds.). Social movements and organized labour: passions and interests. Farnham: Ashgate.

TRAXLER, Franz; SCHMITTER, Philippe. 1995. The emerging europolity and organized interests. European Journal of International Relations, v. 2, n. 1, pp. 191-218.

VISSER, Jelle. 1995. Trade Unions from a comparative perspective. In: VAN RUYSSEVELDT, Joris; HUISKAMP, Rien; VAN HOOF, Jacques (eds.). Comparative industrial and employment relations. London: Sage, pp. 37-67.

WADDINGTON, Jeremy. 2014. Trade union membership retention and workplace representation in Europe: questions on the renewal of trade union organization. Brussels: European Trade Union Institute.

WATERMAN, Peter. 2004. Internacionalismo sindical na era de Seattle. In: ESTANQUE, Elísio et al. (orgs.). Relações laborais e sindicalismo em mudança: Portugal, Brasil e o contexto transnacional. Coimbra: Quarteto, pp. 209-246.

2012. Estudos sobre trabalho global: a necessidade de uma perspectiva emancipatória. Revista Crítica de Ciências Socias, v. 97, pp. 3-22.

WRIGHT, Erik Olin. 2000. Working-class power, capitalist-class interests, and class compromise. American Journal of Sociology, v. 105, n. 4, pp. 957-1002.

ZOLL, Rainer. 1998. Neither social partnership nor class struggle: a plea for new social contracts. European Journal of Industrial Relations, v. 4, n. 1, pp. 103-114. 


\section{SINDICALISMO AINDA CONTA? PODERES SINDICAIS EM DEBATE NO CONTEXTO EUROPEU}

HERMES AUGUSTO COSTA

Resumo: Se o berço europeu do sindicalismo é uma referência incontornável para os estudiosos das relações laborais, o é ainda mais quanto se pretender indagar sobre a relevância do sindicalismo à luz das transformações operadas ao longo da última década no contexto europeu. Num cenário em que, mais do que falar num sindicalismo europeu, faz sentido falar em sindicalismos na Europa, esse texto recupera o legado histórico do sindicalismo e seu sentido plural ("as variedades de sindicalismo", traduzidas em teorias e modelos) para, em seguida, identificar fontes de poder sindical. Argumenta-se que o sindicalismo, apesar dos seus múltiplos fatores de crise, é dotado de fontes de poder que deve capitalizar como forma de ultrapassar suas fraquezas. Como corolário disso, identificam-se quatro temas - representatividade, independência, ação internacional e construção de alianças sociais - a partir da realidade europeia. Mais do que fatores de crise, tais temas são um pretexto para a renovação sindical.

Palavras-chave: Sindicalismo; Europa; Fontes de Poder; Representatividade; Independência; Ação Internacional; Alianças Sociais.

\section{IS TRADE UNIONISM STILL WORTH IT? TRADE UNION POWERS IN DEBATE WITHIN THE EUROPEAN CONTEXT}

Abstract: If the European legacy of unionism is a must-have reference for scholars of labor relations, it is even more when inquiring about the relevance of trade unionism in the light of the transformations over the last decade in the European scenario. In a scenario in which, more than talking about an European trade unionism, it 
makes sense to talk about trade unionism in Europe, this paper retrieves the historical legacy of trade unionism and its plural sense ("the varieties of unionism", translated into theories and models) in order to then identify the sources of union power. It argues that the trade union movement, despite its multiple crisis factors, is able to capitalize sources of power as a way to overcome its weaknesses. Consequently, four themes are identified - representativeness, independence, international action and construction of social alliances - based on the European reality. More than crisis factors, such themes are a pretext for the renewal of trade unionism.

Palavras-chave: Trade unionism; Europe; Sources of Power; Representativeness; Independence; International Action; Social Alliances.

Recebido: 03/06/2018 Aprovado: 17/07/2018 